\title{
A involução dos direitos previdenciários das crianças e adolescentes: uma leitura a partir dos direitos humanos
}

\author{
The devolution of the welfare rights of children and \\ adolescents: a reading from the view the human rights
}

\author{
Nívia Cardoso Guirra Santana* \\ Isabel Maria Sampaio Oliveira Lima**
}

\section{Resumo}

A seguridade social pode ser conceituada como instrumento de proteção, sendo a previdência a técnica para resguardar o indivíduo e seus dependentes, fortalecendo-os quando do enfrentamento de certas contingências da vida. Reflexo do desenvolvimento dos direitos humanos e do Estado de Bem-Estar Social, a previdência conserva uma gama de características destes e agrega outras, sempre espelhando os princípios de proteção, universalidade na cobertura e no atendimento, seletividade e necessidade. $\mathrm{O}$ objetivo deste artigo é discutir a proteção previdenciária destinada às crianças e aos adolescentes sob guarda e a verificação do cumprimento das normas supranacionais ratificadas pelo Estado brasileiro em um cenário de crise do Welfare State. A estratégia metodológica adotada foi de natureza qualitativa, observando-se os procedimentos de revisão legislativa e jurisprudencial. Inicialmente, levantou-se a literatura nacional e a internacional e, em seguida, aplicou-se o critério históriconormativo na análise da legislação previdenciária específica do século XIX ao século XXI. Os resultados indicam que, embora o desenvolvimento dos direitos humanos tenha sido a tônica do século passado, e a sua efetivação o principal

Mestre em Família na Sociedade Contemporânea pela Universidade Católica do Salvador. Salvador - Bahia - Brasil. E-mail: nivia@silveiraguirra.com.br.

* Doutora (ISC-UFBA), Profa. do PPGFSC-UCSAL, Juíza de Direito, Líder do Grupo de Pesquisa Direitos Humanos, Direito à Saúde e Família (UCSAL-CNPQ), Orientadora. Salvador - Bahia Brasil. E-mail: isabelmsol@gmail.com 
foco do estudo científico em tempos presentes, a proteção social previdenciária destinada às crianças e adolescentes se mostra em descompasso com o ideal humanitário, pela progressiva restrição de beneficiários. Essa restrição está em desacordo com o princípio de não retrocesso social e com as garantias específicas conquistadas internacional e nacionalmente para esse segmento populacional.

Palavras-chave: Direitos humanos. Previdência social. Criança e adolescente.

\section{Abstract}

Social Security can be conceptualized as an instrument of protection, considering security as a technique to help individuals and their beneficiaries become safe, strengthening them when they are dealing with certain contingencies of life. Having reflected the development of human rights and followed the rules of Social Welfare, Social Security has a wide range of their characteristics and adds others, always reflecting the principles of protection, service and coverage universality, as well as selectivity and need. The aim of this article is to discuss the social security protection for children and adolescents under custody and the observance whether the supranational human rights rules ratified by the Brazilian Country have been followed under a current welfare state crisis. The methodological strategy adopted was qualitative in which procedures for judicial and legislative reviews were observed. At first, the national and international literature was visited and then a historical and legal criterion was applied in the analysis of the specific social security legislation in the nineteenth and the twenty-first century. The results indicate that although the development of Human Rights have been the tone of the last century and its implementation the main focus of scientific studies at the moment, the social protection and social security for children and adolescents shows up at odds with the ideal humanitarian due to the progressive restriction of beneficiaries. This restriction is at odds with the the principle of the prohibition of social retrocession and specific safeguards conquered internationally and nationally for this population segment.

Keywords: Human rights. Social security. Children and adolescents. 


\section{Introdução}

A seguridade social é frequentemente conceituada como instrumento de proteção (CASTRO; LAZZARI, 2010; MARTINEZ, 2010), sendo a previdência a técnica para resguardar o indivíduo e seus dependentes, fortalecendo-os quando do enfrentamento de certas contingências da vida, tais como invalidez, idade avançada ou morte. Reflexo do desenvolvimento dos direitos humanos e do Estado de Bem-Estar Social, a previdência conserva uma gama de características destes e agrega outras, sempre espelhando os princípios de proteção, universalidade na cobertura e no atendimento, seletividade e necessidade. Esses critérios, embora sejam acolhidos na atualidade, foram construídos a partir da compreensão e do desenvolvimento dos direitos humanos - balizadores de uma proteção social institucionalizada -, a fim de proteger os cidadãos não apenas contra as arbitrariedades estatais (direitos de liberdade), mas como forma de coagir o Estado à concessão de prestações, com vistas à justiça, eliminação da pobreza e dependência (direitos sociais).

O objetivo deste artigo é discutir a proteção previdenciária destinada às crianças e aos adolescentes, e a verificação do cumprimento das normas supranacionais ratificadas pelo Estado brasileiro em um cenário de crise do Estado de Bem-Estar Social. Para a delimitação dos direitos previdenciários da criança e do adolescente, considera-se importante a verificação de sua natureza e aproximação ou distanciamento com os direitos humanos. A partir da identificação de pontos de convergência, torna-se possível avaliar a constitucionalidade dos critérios includentes e excludentes, e a possibilidade de aplicação do princípio da reserva do possível em matéria previdenciária.

Estabelecendo-se o posicionamento dos direitos previdenciários no ordenamento jurídico nacional e internacional, impende avaliar os beneficiários de tais direitos. A elaboração das políticas públicas de proteção infantil passa pela inserção das crianças e dos adolescentes no seguro social, conforme previsão expressa da Convenção Internacional dos Direitos da Criança (CDC), em seu art. 26, 1 e 2, e do Estatuto da 
Criança e do Adolescente (ECA). A necessidade de contemplação dos direitos previdenciários infantis assume caráter de imprescindibilidade, pela natureza de direito social fundamental, potencializado quando os beneficiários são crianças e adolescentes, sujeitos de direito a quem a norma constitucional outorga especial visibilidade e cuidado.

A análise histórico-normativa da legislação previdenciária, desde os tempos do Império, fornece um painel explicativo de sua evolução. Configura-se possível a verificação do cumprimento das garantias constitucionais previdenciárias, e de que forma e em que situações fáticas tais crianças e adolescentes foram ou poderiam ser considerados dependentes previdenciários. A estratégia metodológica adotada foi de natureza qualitativa, observando-se os procedimentos de revisão legislativa e jurisprudencial. Inicialmente, levantou-se a literatura nacional e a internacional e, em seguida, aplicou-se o critério históriconormativo na análise da legislação previdenciária específica do século XIX ao século XXI. A partir dessa fase, completou-se a pesquisa em literatura específica publicada.

Os resultados indicam que, embora o desenvolvimento dos direitos humanos tenham sido a tônica do século passado, e a sua efetivação o principal foco do estudo científico em tempos presentes, a proteção social previdenciária destinada às crianças e aos adolescentes se mostra em descompasso com o ideal humanitário, pela progressiva restrição de seus direitos. Essa restrição está em desacordo com as garantias específicas conquistadas internacional e nacionalmente para esse segmento populacional, evidenciando a necessidade de provocação científica para a expansão de tais direitos em uma perspectiva futura.

\section{Da natureza do direito à previdência social: direitos humanos}

Situar o direito previdenciário como parte dos direitos humanos e fundamentais implica na consolidação de suas características e alcance normativo no plano nacional e internacional. No plano supranacional, 
o direito à previdência social se encontra reconhecido como direito humano por vários instrumentos internacionais, como implicitamente previsto na Declaração dos Direitos do Homem, de 1948, que o intitula como direito à segurança, porém, não à segurança individual, mas à proteção social das contingências justificadoras, como desemprego, doença, invalidez, viuvez e velhice, com o objetivo idêntico ao da previdência social, qual seja, a "substituição dos meios de subsistência perdidos em circunstâncias fora do seu controle" (GUIRRA SANTANA; LIMA, 2010, p. 4).

Delimitando o locus da previdência social de forma explícita, o Pacto Internacional dos Direitos Econômicos, Sociais e Culturais, produzido em 1988 e ratificado pelo Brasil em 1992, reconhece o direito de toda pessoa à previdência social, inclusive ao seguro social. No mesmo entendimento, o protocolo adicional à Convenção Americana de Direitos Humanos, ratificado em 1996, também conhecido como Protocolo de San Salvador, dedica o seu artigo $9^{a}$ para determinar que:

Toda pessoa tem direito à previdência social que a proteja das consequências da velhice e da incapacitação que a impossibilite, física ou mentalmente, de obter os meios de vida digna e decorosa. No caso de morte do beneficiário, as prestações da previdência social beneficiarão seus dependentes.

A Constituição Federal de 1988 (CF/88) eleva o princípio da dignidade da pessoa humana a fundamento da República brasileira. Tal marco legal demonstra o posicionamento interno em consonância com a Declaração Universal dos Direitos do Homem - da primazia do homem em relação ao próprio Estado. Para Piovesan (2011, p. 417), os direitos humanos, na CF/88, "surgem como tema global", sendo automaticamente incorporados e passando a apresentar hierarquia constitucional, com aplicabilidade imediata.

Ao fim de um regime militar totalitário no Brasil, tal posicionamento se mostra essencial ao Estado Democrático de Direito, o qual enxerga no ordenamento jurídico, mais que um pensamento conservador e legalista 
- meio de coerção para manutenção do status quo -, um instrumento que assegura os direitos subjetivos do indivíduo, em especial os eminentemente fundamentais, como à vida, liberdade e igualdade, com o objetivo de uma sociedade justa e solidária.

Os direitos fundamentais encontram na dignidade da pessoa humana o seu substrato, sendo considerados fundamentais, mesmo os não positivados, quando assumem intrínseca relação com a dignidade. Os direitos sociais se situam em capítulo próprio do título dos direitos fundamentais, o que evidencia sua condição de verdadeiro direito fundamental e põe fim a uma discussão em que, salvo raras exceções, predominava o entendimento de que esses direitos, como se encontravam positivados tão somente no título da ordem econômica e social, não desfrutavam de força vinculativa própria dos direitos fundamentais, sendo-Ihes reconhecida natureza meramente programática. A fundamentalidade dos direitos sociais é majoritariamente aceita entre os constitucionalistas, como em Cunha Junior (2010), Meireles (2008), Sarlet (2009) e Silva (2002).

O Estado a serviço do homem e não o homem subjugado pelo Estado é o reflexo da inserção do princípio da dignidade da pessoa humana como princípio constitucional, vinculando a autoridade executiva a rigoroso controle. $\mathrm{Na} \mathrm{CF} / 88$, a dignidade da pessoa humana se encontra presente como fundamento do Estado, à frente dos objetivos da República, deixando de ser mero objetivo para ser razão de ser da própria existência do Estado. Revela também a concepção inovadora e o locus privilegiado dos direitos humanos, que passam pela revisão da noção tradicional de soberania absoluta do Estado. Essa soberania, agora em processo de relativização, na medida em que seriam admitidas intervenções no plano nacional em prol da proteção dos direitos humanos, implicaria na transferência de uma concepção "hobbesiana" de soberania para uma concepção "kantiana”, centrada na cidadania universal (PIOVESAN, 2004).

A localização normativa dos direitos sociais vem na esteira do pensamento do Estado de Bem-Estar Social (Welfare State), que posiciona 
os direitos subjetivos do indivíduo não apenas como abstenção estatal, mas, principalmente, partindo de uma atitude ativa deste para assegurar direitos de conteúdo prestacional. O que distinguiria o direito social do direito de defesa é que o segundo se traduziria em uma abstenção do Estado, na finalidade de resguardar o indivíduo de investidas abusivas. Os direitos sociais teriam como objeto um atuar permanente do Estado para ofertar uma prestação positiva, de natureza material ou fática, com vistas a garantir ao indivíduo o mínimo existencial, proporcionandoIhe, em consequência, os recursos materiais indispensáveis para uma existência digna (CUNHA JUNIOR, 2010).

O acolhimento da previdência social como direito fundamental, superando a ideia de "segunda geração", representa a inserção da temática da proteção social na agenda dos direitos humanos, com as consequências hermenêuticas e os termos de políticas públicas daí advindos. A importância de se pensar o direito previdenciário como direito fundamental também é decisiva para a extensão e interpretação de suas normas. A escolha de beneficiários da previdência social passa a ter como parâmetro menos as regras de um direito securitário e mais a justiça social, incluindo as camadas mais desfavorecidas ou frágeis, como crianças e adolescentes que dependam economicamente de seus mantenedores.

Os direitos sociais, por tais qualidades, exigiriam a intervenção ativa e prolongada do Estado, sendo promocionais e projetados para o futuro, impondo ao interpretador da norma a utilização de outros critérios, e não apenas os critérios de interpretação tradicionalmente destinados à proteção dos direitos e garantias individuais (NASCIMENTO, 2007). Com a atuação positiva do Estado para a concretização dos direitos de conteúdo prestacional, a nova postura do intérprete frente à norma deve traduzir-se em uma atividade constitutiva, e não meramente declaratória, observando princípios constitucionais, normas internacionais de direitos humanos e, essencialmente, a dignidade da pessoa humana.

A leitura dos direitos fundamentais não se esgotaria em uma mera interpretação, mas na sua concretização. Daí a impossibilidade da hermenêutica tradicional, isoladamente, contribuir para uma efetivação 
desses direitos. Por isso importa utilizar os métodos tradicionais e os novos, sem esquecer que interpretar a Constituição é concretizá-la. Essa atividade se funda em princípios interpretativos, dentre os quais se destaca o princípio da unidade da Constituição, pois preserva o espírito constitucional, especialmente quando relacionado ao direito fundamental, colocando-o em uma condição de prestígio e autoridade (GUERRA, 2005; EMERIQUE, 2005).

Savaris (2011, p. 35) adverte para a inconveniente utilização da concepção utilitarista a fim de orientar o processo interpretativo do direito previdenciário, já que ela contrapõe a eficiência econômica ao reconhecimento dos direitos fundamentais, subordinando os últimos "a objetivos de preservação de um interesse social geral, fundado em critérios agregados de desenvolvimento (renda per capita nacional, PIB per capita), não se levando em conta a situação específica dos socialmente excluídos".

A utilização de uma interpretação que pondere fatores como a utilidade financeira da medida para fins de restrição de benefícios não deve ser utilizada em matéria previdenciária por escapar da noção de dignidade da pessoa humana em elevação de uma suposta dignidade coletiva, que não pode ser verificada empiricamente. Ultrapassada a utilização de uma interpretação utilitarista e baseada em critérios não jurídicos para a aplicação dos direitos sociais, o alcance, os efeitos e as consequências da criação, a extinção, restrição ou extensão dos direitos previdenciários, no conteúdo legislativo, devem ser analisados a partir de uma referência potente e inescapável - a dignidade da pessoa humana.

Conforme elucida Meireles (2008), os direitos sociais, independentemente da forma de sua manifestação, têm por finalidade a criação e a garantia de uma igualdade entre os indivíduos e, por isso, de uma liberdade material (e não apenas formal). Esses seriam direitos que buscam a justiça social, entendendo tal termo como de interesse de toda coletividade. As alegações de que direitos prestacionais seriam parte da norma de direito fundamental já foi refutada por diversos autores, como 
Novais (2010, p. 176), que entendeu ser "destituída de fundamentação constitucional a tentativa de recusa de natureza jusfundamental a estes direitos e, consequentemente, aos direitos sociais, com base no apelo formalista à pretensa natureza infraconstitucional ou não constitucional dos direitos a prestações". Vinculando-se o direito previdenciário aos direitos humanos e fundamentais, a utilização de critérios meramente econômicos ou outros que escapem à dignidade da pessoa humana implica na restrição dessa liberdade material e, consequentemente, na inaplicabilidade da medida.

O prestígio e a autoridade dos direitos fundamentais não se restringem à sua interpretação, mas atingem outros pontos, como a aplicabilidade imediata de seus ditames e a proibição de retrocesso das conquistas já asseguradas. O reconhecimento de um direito como fundamental implica dizer que a aplicabilidade de seus conteúdos normativos é imediata, não necessitando de norma infraconstitucional que lhe atribua poder cogente, podendo o cidadão buscar no Poder Judiciário, em caso de descumprimento ou não cumprimento, a satisfação prometida em sede constitucional. Portanto, o direito se encontra dotado de "densidade suficiente" para ser feito valer na ausência de lei ou mesmo contra a lei, o que não significa afirmar que a mediação legislativa se mostra desnecessária ou irrelevante. Uma vez formulada pelo Estado a legislação concretizadora do direito fundamental social, que se apresenta em face desse direito como uma "lei de proteção", a ação do Estado se transforma em um dever mais abrangente: o de não eliminar ou revogar essa lei (QUEIROZ, 2006 apud CANOTILHO, 1997).

A desnecessidade de norma ordinária regulamentadora que lhe fixe os caracteres de atuação, por si só, já atribui ao direito social uma eficácia plena libertadora, já que, para ser assegurado ao cidadão comum, não dependeria dos trâmites e do conhecido jogo de poderes e influências que envolvem o processo legislativo. Como informado por Meireles (2008), todos os bens jurídicos delineados no art. $6^{\circ}$ devem ser tutelados, prima facie, pela ordem jurídica, e todas as que se voltem contra a tutela estão, também prima facie, proibidas. Para Alexy (2011), 
essa natureza de direito prima facie pressupõe que qualquer restrição não pode levar ao seu esvaziamento.

A eficácia imediata se sustenta também no pilar que o núcleo essencial dos direitos sociais já realizados e efetivados pelo legislador se encontra constitucionalmente garantido. Quaisquer medidas estatais que, na prática, resultem em anulação, revogação ou aniquilação pura e simples desse núcleo essencial estariam desprovidas de poder ou efetivação. Assim, encontrar-se-iam a liberdade de conformação do legislador e sua inerente autorreversibilidade limitadas pelo núcleo essencial já realizado (SARLET, 2010).

O direito social regulamentado por legislação infraconstitucional estaria cristalizado pelos conceitos de bem-estar, justiça social e pela própria natureza de consolidação dos direitos fundamentais, não podendo ser alterado sem compensações e justificativas que legitimem o ato da autoridade legislativa. A proibição de retrocesso social, também chamada de irreversibilidade de direitos sociais, determina que, uma vez consagradas legalmente as prestações sociais, o legislador não pode, posteriormente, eliminá-las sem alternativas ou compensações equivalentes.

Como já tratado em momento anterior (GUIRRA SANTANA; LIMA, 2010), a consagração do direito previdenciário como direito fundamental gera consequências de ordem prática, já que a Constituição não veda a reforma que busque o aperfeiçoamento desses princípios (separação dos órgãos do Estado, descentralização dos poderes e os direitos e garantias individuais), mas uma alteração supressiva ou redutora de sua essência (TAVARES, 2008). Como os direitos sociais são necessários para uma existência digna do homem, acabam por assumir uma função fundamental e passam a ser intitulados direitos sociais do mínimo existencial, enquanto, para além deles, haveria os direitos sociais formais, que devem ser providos com observância da chamada reserva do possível. A eficácia dos direitos fundamentais não estaria sujeita à reserva orçamentária (SARLET, 2010; CUNHA JUNIOR, 2010), o que 
se conjuga com a superação do pensamento utilitarista criticado por Savaris (2011).

Para Dias (2011), pela natureza dos direitos fundamentais, não Ihe poderiam opor argumentos como crise econômica, social, política ou constitucional, principalmente quando da violação ou descumprimento destes nas prestações do sistema de seguridade social. A questão da eficácia dos direitos sociais passa, invariavelmente, pelos princípios que regem os próprios direitos fundamentais e lhe conferem efetividade.

Os princípios da proibição do retrocesso e segurança jurídica se relacionam diretamente com a efetividade do direito social, já que, em determinados casos, e, principalmente, ao se tratar de prestações de previdenciárias, a norma ordinária deverá conter os parâmetros de alcance do benefício. Reduzir a abrangência, eliminar a própria prestação ou retirar determinados grupos de pessoas do círculo de atuação implica em atingir a própria eficácia do direito.

Aos princípios constitucionais que regem os direitos fundamentais, somam-se os princípios próprios da seguridade social, que devem ser observados na análise da aplicabilidade de normas restritivas desses direitos. A seguridade social é regida por uma série de princípios fundantes, previstos no art. 194 da CF/88, entre eles, os da seletividade e da universalidade. Aparentemente paradoxais, em verdade, devem ser interpretados de forma sistêmica, pois um informaria o outro. Universalidade da cobertura seria a extensão da proteção social a todos os eventos de premente reparação, com a finalidade de manter a subsistência de quem dela necessite (CASTRO; LAZZARI, 2010). Assim, de acordo com Sarlet (2010), tal princípio elevaria todas as pessoas, pelo fato de serem pessoas, a titulares de direitos e deveres fundamentais, comportando apenas algumas exceções expressamente estabelecidas pela Constituição.

O princípio da seletividade poderia ser descrito como um critério de responsabilidade, com a existência de uma gradação de prioridade no atendimento das necessidades humanas (ALMEIDA, 2008). Para Ibrahim (2011), a seletividade estaria vinculada à escolha pelo legislador de 
onde aplicar os parcos recursos da lei orçamentária diante das ilimitadas demandas sociais, sendo eleitas as prestações de maior relevância de acordo com os objetivos constitucionais de bem-estar e justiça social. Para Savaris (2011, p. 238), além da seleção das contingências sociais a serem protegidas, trata-se da "seleção para redistribuição em nome da igualdade (redução das desigualdades sociais e promoção da justiça social)".

Entende Tavares (2008) que a Constituição não vedaria a reforma que busque o aperfeiçoamento desses princípios (separação dos órgãos do Estado, descentralização dos poderes e os direitos e garantias individuais), mas que tentasse uma alteração supressiva ou redutora de sua essência. Sendo os direitos sociais necessários para uma existência digna do homem, acabariam por assumir uma função fundamental e se intitulariam direitos sociais do mínimo existencial, enquanto, para além deles, há os direitos sociais formais, que devem ser providos com observância da chamada reserva do possível.

A limitação ao princípio da seletividade encontrar-se-ia na dignidade da pessoa humana e na preservação do mínimo existencial, especialmente dos sujeitos de direito mais frágeis - as crianças e os adolescentes dependentes economicamente. Nesse pensamento, a proteção social previdenciária deveria ser mensurada segundo critérios de reparação, necessidade e prioridade, pois seria substituta da renda mensal responsável pela subsistência dos segurados. A escolha dos dependentes previdenciários, de igual sorte, deveria obedecer aos mesmos critérios, sempre depois de cumprido o critério contributivo, por ser essencial à manutenção do sistema e também princípio constitucional. A restrição de dependentes já consagrados não atende a tal princípio, já que o custeio prévio foi definido quando da instituição da prestação, como chama atenção Ibrahim (2011).

A restrição de direitos previdenciários em geral e, especialmente, dos direitos previdenciários infanto-juvenis deve ser analisada como de ordem excepcional e apenas admitida quando vise reparar e ampliar a proteção em outra ordem. Assim, a restrição da proteção previdenciária 
às crianças e aos adolescentes não prescinde de justificativas que extrapolem a questão econômica, necessitando, para a sua validade, de outras medidas, na forma de políticas públicas, que ofertem melhor proteção, ainda que através de outros direitos fundamentais. Como o princípio da proteção à vida e sua dignidade exige ser realizado na maior medida, nas palavras de Alexy (2011, p. 453), seria "possível falar de uma violação a direito fundamental por parte do Estado, que surge quando ele não cumpre de forma suficiente o seu dever de proteção", uma análise subjetiva que pôde ser observada pelo autor nos julgamentos do Tribunal Constitucional Federal alemão.

Firmada a natureza de direito humano e fundamental do direito previdenciário e suas características de aplicabilidade imediata, impossibilidade de retrocesso social, ausência de submissão à reserva do possível e, em última instância, impossibilidade de afronta à dignidade das crianças e dos adolescentes, reconhecidos como detentores do direito à proteção especial, passa-se à análise do desenvolvimento desse ramo do direito, especialmente dos direitos previdenciários infantis.

\section{Breve panorama histórico-legislativo do direito previdenciário da criança e do adolescente}

A análise da linha temporal, em que os diplomas normativos se sucederam e ajudaram a formar o que, atualmente, está condensado no chamado sistema de seguridade social brasileiro permite estabelecer uma perspectiva ampla e diagnosticar a ocorrência de evolução dos direitos previdenciários, com ênfase nos direitos subjetivos de natureza prestacional, tendo como titulares crianças e adolescentes. Contemplar a cobertura legal ofertada, desde as primeiras normas protetivas de natureza previdenciária, para confrontá-la com as escolhas no plano internacional, retratadas pelas Convenções e Declarações de Direitos Humanos, permite um diálogo entre as políticas legislativas adotadas pelo Brasil e sua (in)congruência com o plano normativo internacional, o qual, na maioria das vezes, formalmente integra. 
O desenvolvimento da proteção social no Estado brasileiro, especialmente a proteção previdenciária, ocorre a partir do final do século XIX, para atender a reinvindicações políticas e econômicas, a exemplo do Seguro Social Alemão, de Bismarck (DERZI, 2009). A primeira norma ordinária a prescrever benefícios de natureza previdenciária destinados aos dependentes dos trabalhadores foi a Lei n 3.397, de 24 de novembro de 1888, instituidora da Caixa de Socorros para os trabalhadores das estradas de ferro do Império. Tal norma previa o direito a uma pensão destinada às famílias dos empregados que faleciam. Essa previsão era de natureza genérica, sem estabelecimento de requisitos, vínculos ou critérios para o enquadramento dos indivíduos na denominação "família". Castro e Lazzari (2010, pp. 67-68) esclarecem que as regras de natureza previdenciária criadas no século XIX eram isoladas, apesar da previsão constitucional de 1824 sobre a "garantia dos socorros públicos", aparentemente de natureza programática.

O Decreto n० 942-A, de 31 de outubro de 1890, criando o Montepio Obrigatório dos Empregados do Ministério da Fazenda, estabelece quais seriam os membros da família eleitos como beneficiários da pensão. Diante da concepção de família da época, sob a égide do pensamento então vigente na véspera da primeira Constituição do Brasil, os beneficiários seriam a viúva, os filhos menores de 21 anos não emancipados, as filhas solteiras domiciliadas com o trabalhador ou que não convivessem no mesmo domicílio do falecido, mas tivessem o consentimento deste. As filhas viúvas maiores e os netos menores ou netas solteiras também eram considerados dependentes, desde que convivessem com o contribuinte. Os sobrinhos menores e as sobrinhas solteiras, desde que a mãe - irmã do contribuinte - fosse falecida, também se encontravam na última linha de preferência, sendo beneficiários apenas na ausência dos outros familiares.

Na esteira de criação de normas protetivas, a Lei $n^{\circ} 217$, de 29 de novembro de 1892, instituiu a aposentadoria por invalidez e a pensão por morte dos operários do Arsenal da Marinha do Rio de Janeiro, e previa como dependentes a viúva, os filhos menores e filhas, mãe ou irmã 
solteira do contribuinte. O filho menor perdia o direito aos 18 anos ou, se estudante, aos 21 , exceto se comprovado vício reprovado, ou se até os 11 anos fosse inteiramente analfabeto na data do óbito do segurado. A inclusão de critérios morais como impeditivos do recebimento de benefícios passa a ser uma constante na previsão normativa até meados do século $X X$, quando substituídos pelo entendimento de proteção integral da criança em confronto com os contornos legais punitivos.

A inclusão de crianças e adolescentes como beneficiários de trabalhadores pressupunha a conjugação de dois critérios: o limite etário e o gênero. As filhas mulheres, mesmo com a maioridade, não perdiam o acesso aos benefícios decorrentes do falecimento do contribuinte, desde que se mantivessem solteiras. No entanto, os filhos ou netos do sexo masculino perdiam o benefício antes da maioridade caso não fossem estudantes ou, quando estudantes, perdiam ao completar 21 anos. Configura-se contraditória a amplitude no estabelecimento dos atingidos pela proteção previdenciária, sendo estendida aos netos(as), irmã(os) e sobrinhos(as), bastando o critério etário e a inexistência de outros dependentes. A restrição maior circunda a questão de gênero, desvinculando de laços próximos de parentesco e da família nuclear.

Para uma expressiva quantidade de estudiosos (DERZI, 2009; SIMM, 2005), a primeira norma que instituiu um regime de previdência social no Brasil, compreendendo aposentadorias e pensões, foi o Decreto $n^{\circ} 4.682 / 1923$. A denominação atribuída a esse decreto foi "Lei Eloy Chaves", nome do autor do projeto, que determinou a criação de uma Caixa de Aposentadoria e Pensões para os empregados de cada empresa ferroviária. Ponto de partida da previdência social propriamente dita, previa como beneficiários a viúva, o viúvo inválido, os filhos, os pais e irmãs solteiros, na ordem de sucessão legal. No caso dos filhos, perdiam tal atributo aos 18 anos; para as filhas ou irmãs, apenas ao contraírem matrimônio, restringindo a extensão dos dependentes, com exclusão de netos e sobrinhos, mas seguindo integralmente, em relação aos filhos e irmãs, o já previsto nas caixas particulares da previdência de 1888,1890 e 1892. 
ALei 5.109, de 20 de dezembro de 1926, que estendeu o Regime da Lei Eloy Chaves aos portuários e marítimos (IBRAHIM, 2011), incluiu um novo critério de configuração da qualidade de beneficiário: a dependência econômica exclusiva da renda do associado. Em 1931, o Decreto n ${ }^{\circ}$ 20.465 estendeu o Regime da Lei Eloy Chaves aos empregados dos demais serviços públicos, além de consolidar a legislação referente às Caixas de Aposentadorias e Pensões. Em relação aos dependentes, introduziu a previsão da "menor designada", porém, destinada apenas à pessoa do sexo feminino, com parentesco até $3^{\circ}$ grau, mediante a devida comprovação da dependência exclusiva da economia do falecido (BRASIL, INSS, 2012, on-line).

A possibilidade legalmente atribuída ao segurado para exercício da própria vontade quando da designação dos seus beneficiários se manteve no Decreto $n^{\circ} 22.872$, de 29 de junho de 1933. Esse decreto criou o Instituto de Aposentadoria e Pensões dos Marítimos, passando a ter como requisitos formais para a designação a declaração feita de próprio punho, com testemunhas, firma reconhecida e registro no Instituto. A vinculação a laços de parentescos e/ou idade não seria requisito, bastando, para tanto, a dependência econômica exclusiva, sendo atribuída a metade do valor da pensão ao designado.

A Constituição de 1934, muito lembrada por prever o custeio pelos trabalhadores, empregadores e Poder Público, também se destaca por determinar a instituição de previdência para os casos de velhice, invalidez, maternidade, acidentes de trabalho ou morte. Ela elege os riscos sociais que são mantidos até os dias atuais. Já a Constituição de 1937 não apresenta inovações significativas, substituindo a expressão "previdência" por "seguro social" e o risco "morte" por "seguro de vida", porém, tais alterações parecem não ter influenciado as normas seguintes, que privilegiaram a expressão "previdência" e o risco "morte", como se percebe na Constituição de 1946, que retoma o direito à previdência e inclui o adjetivo "social".

O Decreto-Lei $\mathrm{n}^{\circ}$ 288, de 23 de fevereiro de 1938, criou o Instituto de Previdência e Assistência dos Servidores do Estado e aumentou a 
idade do beneficiário filho para 22 anos. O Decreto-Lei $\mathrm{n}^{\circ} 1.355$, de 19 de junho de 1939, que criou o Instituto de Aposentadoria e Pensões dos Operários Estivadores, trouxe algumas inovações, como a restrição etária da designação de pessoa do sexo masculino, desde que menor de 18 anos ou inválida e na falta de outros dependentes, bem como de irmãos menores de 18 anos ou inválidos. Manteve, ainda, a previsão de designação de menor sem parentesco, que perduraria até o final do século. Esse critério designador de competência foi preservado pela Lei Orgânica de Previdência Social, de n³.807, de 26 de agosto de 1960, cuja finalidade era uniformizar a prestação previdenciária, buscando abranger todos os trabalhadores assalariados, autônomos, profissionais liberais, empresários e outros (DERZI, 2009).

A ampliação mais importante do acesso à proteção previdenciária pelas crianças e adolescentes advém do Decreto-Lei n 66, de 21 de novembro de 1966, que equipara aos filhos de qualquer condição, os menores de 18 anos ou inválidos as filhas solteiras de qualquer condição, menores de 21 anos ou inválidas, e, mediante declaração escrita do segurado ao enteado, o menor que, por determinação judicial, estava sob sua guarda ou que se encontrava sob sua tutela e não possua bens suficientes para o próprio sustento e educação. A inclusão do enteado, menor sob guarda e tutela, como alvo da proteção previdenciária permanece em todas as normas posteriores, até o final do Século XX. A Constituição de 1967 não inova em absoluto os aspectos protetivos da Constituição anterior.

A última Consolidação das Leis de Previdência Social, de 1984, incluiu o idoso como dependente designado. Digno de destaque na referida norma é a concorrência entre a pessoa designada e os filhos menores ou inválidos do segurado. O designado, na ausência de esposa ou marido inválido, e se autorizado pelo segurado, mediante declaração escrita, poderia concorrer com os seus filhos menores ou inválidos. Percebe-se a ocorrência de um dependente privilegiado, que excluiria os pais ou irmãos do direito às prestações, além de repartir igualmente com os filhos. 
A Constituição Federal de 1988 elevou a previdência social à categoria dos direitos e garantias fundamentais. Assim, sua previsão está contida no Capítulo II, art. $6^{\circ}$, como Direito Social, refletindo a conformação da Declaração Universal dos Direitos do Homem, especialmente o seu art. XXV (GUIRRA SANTANA; LIMA, 2010). As normas seguintes à $\mathrm{CF} / 88$ trataram de fundar as instituições responsáveis pela administração e provimento do direito humano à seguridade social, sendo criado, em junho de 1990, o Instituto Nacional do Seguro Social (INSS) e, em 1991, o Plano de Benefícios da Previdência Social (Lei ${ }^{\circ}$ 8.213), de 24 de julho de 1991, regulamentada pelo Decreto $n^{\circ} 357$, de 7 de dezembro de 1991, vigente até os dias atuais.

A redação original da Lei 8.213/91 firmou o critério etário sem distinção de gênero para filhos e irmãos menores de 21 anos ou inválidos, e da pessoa designada menor de 21 anos ou maior de 60 ou inválida, respeitando essa ordem, chamada de classes, para a percepção do benefício. A superação de qualquer diferenciação relativa a gênero advém da consagração do princípio da igualdade na nova Constituição. $\mathrm{Na}$ chamada primeira classe, manteve-se o enteado; o menor que, por determinação judicial, estivesse sob a guarda do segurado; e o menor que estivesse sob sua tutela e não possuísse condições suficientes para o próprio sustento e educação - em todos os casos, mediante declaração do segurado e comprovação da dependência econômica.

A Lei 8.213/91 tem como característica importante a ampliação de alguns caracteres protetivos e a manutenção de outros, podendo ser considerada a norma mais extensa e representativa, em sua redação original, da inserção da criança e do adolescente como titulares de direitos previdenciários. Primeiramente, ela uniformizou o requisito etário, que, originalmente, variava entre 16 e 21 anos, elegendo este último como limite para o recebimento de benefícios. O segundo ponto importante foi a extinção dos critérios de gênero, para manter a igualdade em relação aos filhos, retirar o estado civil da filha como excludente de dependência e firmar o critério de dependência econômica para as crianças e adolescentes equiparadas a filhos. Consubstanciou-se, 
assim, no plano previdenciário o princípio dos direitos humanos adotado na Carta Magna, ratificando a proteção prevista na Lei $n^{\circ}$ 8069/90.

Condensando a previsão de dependência, o Capítulo I, Seção II, estabelece os beneficiários das prestações, dividindo-os em classes. Seriam os sujeitos da primeira classe: cônjuge, companheira, companheiro, e filho de qualquer condição menor de 21 anos ou inválido. Na segunda classe, estariam os pais, e na terceira classe, o irmão de qualquer condição menor de 21 anos ou inválido. Por fim, a referida norma previa o designado, que seria o menor de 21 anos ou maior de 60 ou inválido escolhido pelo segurado para figurar entre os seus dependentes. De igual sorte, equiparar-se-iam ao filho como dependente de primeira classe, mediante declaração do segurado, o menor que estivesse sob sua guarda por determinação judicial e o menor sob tutela que não possuísse condições para o próprio sustento.

A norma infraconstitucional reflete os ideais de proteção integral da Convenção Internacional dos Direitos da Criança (1989), reconhecendo o seu direito à vida, ao desenvolvimento pleno, e o papel do Estado, no que Alexy (2011) definiu como dever de proteção diante de um direito subjetivo definitivo e vinculante, in casu, o direito a um mínimo existencial, face ao risco de perda dos meios de assegurá-lo pela morte de seu provedor.

A redação original da Lei 8.213/91, contudo, teve vigência por menos de quatro anos, sendo alterada pela Lei $n^{\circ}$ 9.032, de 28 de abril de 1995, que estendeu para o irmão o critério de não emancipação e excluiu do rol de beneficiários o menor ou idoso designado, ficando assegurado o direito adquirido até aquela data. A criação de um critério negativo para o filho - o de não emancipação - inverte o dever de comprovação de necessidade, pois, sendo emancipado, não seria dependente econômico. A mudança legislativa, aparentemente inofensiva por prever requisito de dependência econômica que já se espera, atribui um ônus de produção de prova à criança ou jovem de 18 a 21 anos, que teria o encargo da comprovação de que não possuiria economia própria. 
A designação deixou de ser possível no direito previdenciário. Essa circunstância atende à sua autonomia, já que a dependência previdenciária não se confunde com o conceito de herança do direito civil, porém, a eleição do laço de parentesco sanguíneo como critério maior de dependência previdenciária é realizada à revelia da noção de necessidade real ou dependência econômica. Nas palavras de Derzi (2004, pp. 223-224), a escolha do legislador em "privilegiar o interesse familiar em detrimento do critério de real dependência econômica ou sobrevivência" passa a ser a tônica das restrições iniciadas pela Lei $\mathrm{n}^{\circ}$ 9.032/95.

Em 1997, a Lei 9.528, resultado da conversão da Medida Provisória $n^{\circ}$ 1.596-14/ 1997, alterou novamente a redação do art. 16 da Lei de Benefícios, substituindo a expressão "que não possua condições suficientes para o próprio sustento e educação" por "comprovada a dependência econômica"; e subtraindo a expressão "o menor que, por determinação judicial, esteja sob a sua guarda". Essa adequação do legislador giza a natureza da dependência econômica como critério eletivo para o benefício, embora atue para restringir o acesso ao direito previdenciário do menor que se encontre em guarda, mesmo que ele dependa economicamente do segurado.

O Brasil incorporou tardiamente ao seu arcabouço jurídico a Convenção 102 da Organização Internacional do Trabalho (OIT). Criada em 1952, ela foi aprovada em 2008 e ratificada em 2009. A Convenção, em alguns pontos ultrapassada em virtude do contexto histórico e cultural em que foi criada, especialmente quando do tratamento das questões de gênero, reafirma o lugar da criança e do adolescente na proteção previdenciária como um lugar privilegiado, destinado à manutenção de crianças, seja com o pagamento periódico ou no fornecimento de alimentos, roupas, habitação, local para férias e assistência domiciliar; ou uma combinação das duas prestações: in natura e monetária.

Com a Lei 12.470/2011, e após longo período de inércia legislativa no estabelecimento ou restrição de dependentes, o art. 16 foi novamente alterado, incluindo como dependente o filho ou irmão com deficiência intelectual ou mental que o torne absoluta ou relativamente incapaz, 
assim declarado judicialmente. Tal alteração reflete um raro momento de ampliação dos requisitos de ingresso no sistema, resultante do novo conceito de deficiência constante no preâmbulo e no corpo da Convenção sobre Direitos da Pessoa com Deficiência (ONU, 2006).

Dessa breve análise do desenvolvimento histórico-normativo da previdência social brasileira em relação à proteção destinada a crianças e adolescentes, pode-se aferir a restrição de critérios inclusivos para que estes tenham acesso às prestações previdenciárias. Crianças e adolescentes sem grau de parentesco direto, mesmo que dependentes econômicos ou sob guarda, não mais fariam parte da destinação de recursos visando à garantia de sua sobrevivência. Ao mesmo tempo, não se observa, no período de 1991 a 1997, quando das alterações restritivas, a elaboração de políticas públicas para a preservação da sobrevivência digna dessas crianças, em um mecanismo compensatório pela retirada da guarida previdenciária.

A exclusão da criança, tanto a que fora designada pelo segurado quanto aquela sob guarda, conforme as leis de 1995 e 1997, respectivamente, configura o "esvaziamento do direito", consoante a expressão de Alexy (2011, p. 515). Essa restrição de direito fundamental subtrai da criança e do adolescente a possibilidade de exigir do Estado que lhes garanta o mínimo existencial quando da morte de quem dependiam economicamente. Denota, ademais, a negação dos direitos garantidos no art. 227 da CF e no art. $3^{\circ}$ da CDC.

Um dos argumentos mais comumente levantados para a doutrina que defende a exclusão legal reside na existência de fraudes com a finalidade de perpetuação de benefício, ou seja, na concessão de guardas abusivas ou fraudulentas. Sobre tais alegações, a desembargadora Assusete Magalhães (Arguição de Inconstitucionalidade de $\mathrm{n}^{\circ}$ 1998.37.00.001311-0/MA -http://arquivo. trf1.jus.br/default.php?p1=199837000013110 -, publicada no Boletim Informativo de Jurisprudência $n^{\circ} 79$ ) pontuou:

Se eventuais fraudes há, devem ser combatidas pela fiscalização, pela polícia, pelo aparelho preventivo e 
repressivo que o ordenamento jurídico coloca à disposição do Estado, não com a discriminação odiosa efetuada pela legislação previdenciária ora discutida, que joga, ao desamparo, o menor acolhido no seio de uma família substituta.

Nomesmosentido, encontram-seargumentosque chamamatenção para o princípio da seletividade, que autorizaria a escolha legislativa restritiva. Tal princípio, contudo, encontra limites na dignidade da pessoa humana e na preservação do mínimo existencial, especialmente dos sujeitos de direito mais frágeis - as crianças e adolescentes dependentes econômicos. Nesse pensamento, o princípio da seletividade deve ser aplicado segundo critérios de reparação, necessidade e prioridade, pois se trata de substitutos da renda mensal responsável pela subsistência dos segurados. A escolha dos dependentes previdenciários, de igual sorte, deveria obedecer aos mesmos critérios.

A vertiginosa retração dos direitos previdenciários à criança e ao adolescente, especialmente na década de 1990, pode ser considerada um retrocesso em contraponto à evolução dos seus direitos no plano internacional, consolidados de forma primordial pela Convenção Internacional dos Direitos da Criança (1989) e demonstrações de interesse do Brasil em firmar uma imagem protetiva.

Atualmente, projetos como o Plano Nacional de Promoção, Proteção e Defesa do Direito das Crianças e Adolescentes à Convivência Familiar e Comunitária (MDS, 2006) demonstram ser o direito da criança um ponto especial de atenção no campo das políticas públicas. A posição brasileira que, segundo Costa e Rossetti-Ferreira (2009, p. 1) volta a sua atenção para o direito infantil, incluindo em sua "agenda nacional" "diretrizes que garantam o direito à convivência familiar e comunitária e favoreçam a desinstitucionalização de crianças e adolescentes", apresenta uma fissura ideológica quando mantém a restrição destes ao quadro de dependentes previdenciários.

Os direitos previdenciários, principalmente em relação aos dependentes, têm como objetivo salvaguardar determinadas pessoas 
que se encontram em risco social, com a substituição da renda faltante em virtude do falecimento ou reclusão do segurado que possuía tal dever de sustento. Quando se trata de crianças e adolescentes nessa situação de risco, acentua-se o dever de proteção, seja através da previdência, no caso de ser o segurado devedor de alimentos, seja através da assistência social.

A presença dos critérios de reparação, necessidade e prioridade estãoemtotal desconformidade coma restrição/exclusão de determinadas crianças e adolescentes do rol de beneficiários da previdência social. Eleger como política pública essencial o direito da criança e adolescente a uma família na tentativa da desinstitucionalização representa uma proteção de amplo espetro e o fortalecimento das formas de guarda.

\section{Perspectivas do direito previdenciário da criança e adolescente}

Depreende-se que a retirada progressiva da criança e do adolescente do quadro de dependentes previdenciários, iniciada na década de 1990, parece não observar a natureza dos direitos que os contempla, especialmente ao se verificar a inexistência de políticas públicas substitutivas, de modo a resguardar o princípio do não retrocesso social, pertinente aos direitos humanos. A legislação atual previdenciária, de forma controversa, outorga seus benefícios a "dependentes" que podem não depender economicamente do segurado. A presunção de dependência da família consanguínea fere o princípio na dignidade da pessoa humana diante das peculiaridades das realidades socioeconômicas familiares, pois exclui a criança e o adolescente sob guarda, que necessariamente precisam comprovar a dependência econômica, porém, mantém o critério de resguardar o direito de outros dependentes, mesmo na hipótese de ausência de comprovação da efetiva necessidade do benefício. As contingências que geram a razão de ser da previdência social - o risco de perder a sua renda de subsistência em razão da temporária ou definitiva ausência do segurado - cedem lugar ao interesse sucessório stricto sensu. 
Ao privilegiar a família nuclear e a presunção de dependência, a norma previdenciária não atende aos seus princípios básicos de direito humano e fundamental, principalmente o da universalidade. Para Derzi (2004, p. 251), o sistema de seguridade social que se entende universal não poderia ser "engessado". Defendendo a designação do dependente, elucida que a norma anterior previa a criança e o idoso como dependentes designados por serem "pessoas que, por razão da menoridade ou de idade avançada ou incapacidade laboral", estariam "impossibilitadas de viver às suas expensas, necessitando os aportes econômicos do segurado".

O presente estudo observou a inexistência de um olhar específico sobre a inserção de crianças e adolescentes na previdência social tanto na literatura como nas políticas públicas, que têm como principal função "a concretização de direitos de cidadania conquistados pela sociedade e amparados pela lei" (PEREIRA, 2006, p. 101). Pensar em políticas públicas de inserção de crianças e adolescentes como beneficiários da previdência social consagra o princípio da igualdade, da proteção social, e assimila o conteúdo da CDC, especialmente ao considerá-los sujeitos de direito e, por sua vulnerabilidade, os mais passíveis de necessitar da proteção social institucionalizada.

$A$ atenção às novas realidades em que crianças e adolescentes estão inseridos - como parte de famílias em modalidades de formação diversas, muitas vezes, não constituídas pelos seus genitores e, por tal motivo, distante do rol restritivo e rígido da lei previdenciária - reclama com urgência um posicionamento crítico nos âmbitos político e científico. A ideologia liberal, ou neoliberal, que resultou nas reformas, merece uma análise pelo viés dos direitos humanos, para devolver a legitimação dos direitos sociais conquistados pelo Estado de Bem-Estar Social, dissipando a nuvem de "crise constitucional" que ainda hoje perdura nas discussões em torno da seguridade social.

A necessidade de recursos para a manutenção da previdência pode ser percebida como um desafio, e não como impedimento da 
extensão de seu manto protetor às camadas mais carentes, como sugere Pereira (2006). Situação específica que merece atenção é a guarda de crianças e adolescentes que, desprovidos do convívio com os seus genitores, são "guardados", principalmente por seus avós, mas também pela família extensa ou substituta. Essas pessoas em desenvolvimento, além da vulneração de natureza familiar pelo afastamento de seus genitores, ainda estão sujeitas ao desprezo da instituição previdenciária, na hipótese da ausência de seus guardiões. Repensar a situação das crianças e adolescentes e seu lugar na proteção social previdenciária se faz urgente, especialmente considerando-se as crianças que, atualmente, demandam tais benefícios, sem o atendimento de suas necessidades mais básicas.

\section{Referências}

ALEXY, R. Teoria dos direitos fundamentais. São Paulo: Malheiros, 2011.

ALMEIDA, M. V. T. de. Elementos nucleares de previdência social. Belo Horizonte: PUC Minas Virtual, 2008.

BALERA, W. (Org.). Previdência social comentada: lei 8.212/91 e 8.213/91. São Paulo: Quartier Latin, 2008.

CANOTILHO, J. J. G. Estudos sobre direitos fundamentais. 2. ed. Portuguesa. São Paulo: Revista dos Tribunais, 2008.

CASTRO, C. A. P.; LAZZARI, J. B. Manual de direito previdenciário. 12. ed. Florianópolis: Conceito, 2010.

COSTA, N. R. do A.; ROSSETTI-FERREIRA, M. C. Acolhimento familiar: uma alternativa de proteção para crianças e adolescentes. Psicol. Reflex. Crit., Porto Alegre, v. 22, n. 1, 2009. Disponível em: <http://www.scielo. br/scielo.php?script=sci_arttext\&pid=S0102-79722009000100015\&lng= en\&nrm=iso>. Acesso em: 8 ago. 2011.

CUNHA JÚNIOR, D. Curso de direito constitucional. 4. ed. rev. ampl. atual. Salvador: Jus Podivm, 2010. 
DERZI, H. H. Os beneficiários da pensão por morte: regime geral de previdência social. São Paulo: Lex, 2004.

DIAS, C. A. G. Aplicabilidade do princípio constitucional da dignidade humana como direito fundamental nas relações sociais e na cobertura do sistema de seguridade social. Qualit@s Revista Eletrônica, João pessoa, v. 1, n. 1, 2011. Disponível em: <http://revista.uepb.edu.br/ index.php/qualitas/article/viewFile/719/590>. Acesso em: 3 out. 2011.

DÍAZ, M. A. G. La seguridad social en España: situación actual y algunas reflexiones sobre su futuro. Cuadernos de relaciones laborales, Madrid, n. 8, p. 85-105, 1996. Disponível em: <http://dialnet.unirioja.es/ servlet/articulo?codigo=165245>. Acesso em: 20 out. 2011.

GARCÍA LOPEZ, J. M.; PÉREZ FORNIÉS, C. P. La seguridad social española: los problemas del sistema de pensiones. Acciones e Investigaciones Sociales, Saragoça, n. 6, p. 109-126, 1997. Disponível em: <http://dialnet.unirioja.es/servlet/busquedadoc?t=la+seguridad+soc ial+espanola+los+problemas+del+sistema+de+pensiones \&db=3\&td=A RTREV>. Acesso em: 20 out. 2011.

GRAU, E. R. Ensaio e discurso sobre a interpretação: aplicação do direito. 5. ed. São Paulo: Malheiros, 2009.

GUIRRA SANTANA, N. C.; LIMA, I. M. S. O. Direito previdenciário, família e direitos humanos: entre o claro-escuro. In: SEMANA DE MOBILIZAÇÃO CIENTÍFICA,13., 2010, Salvador. Anais... Salvador: UCSal, 2010, p. 365-384

HORVATH JUNIOR, M. Direito previdenciário. 8. ed. São Paulo: Quartier Latin, 2010.

IBRAHIM, F. Z. Curso de direito previdenciário. 16. ed. Rio de Janeiro: Impetus, 2011.

A previdência social e a garantia dos direitos humanos. In: CONGRESSO BRASILEIRO DE PREVIDÊNCIA SOCIAL, 30., 2011, São Paulo. Disponível em: <http://www.Itr.com.br/web/jornal/ previdenciasocial.pdf>. Acesso em: 21 nov. 2011. 
MARTINEZ, W. N. Curso de direito previdenciário. 3. ed. São Paulo: LTr, 2010.

. Dependência econômica na previdência social. Revista IOB Trabalhista e Previdenciária, Porto Alegre, v. 17, n. 216, p. 7-12, jun. 2007.

. Direitos previdenciários na relação homoafetiva. Revista IOB Trabalhista e Previdenciária, Porto Alegre, v. 19, n. 227, p. 14-18, maio 2008.

MEIRELLES, A. C. Eficácia dos direitos sociais. Salvador: Podivm, 2008.

MENDONÇA, A. B.; FERREIRA, O. A. V. A. Eficácia dos direitos fundamentais nas relações privadas. In: NOVELINO, M. Leituras complementares de constitucional: direitos humanos \& direitos fundamentais. 4. ed. ampl. rev. atual. Salvador: Podivm, 2010. p. 295314.

MINAYO, M. C. de S. Avaliação por triangulação de métodos: abordagem de programas sociais. Rio de Janeiro: Fiocruz, 2006.

MINAYO, M. C. de S. et al. Pesquisa social: teoria, método e criatividade. Petrópolis, RJ: Vozes, 1994.

NASCIMENTO, S. Interpretação do direito previdenciário. São Paulo: Quartier Latin, 2007.

NOVAIS, J. R. Direitos sociais: teoria jurídica dos direitos sociais enquanto direitos fundamentais. Coimbra: Ed. Coimbra, 2010.

QUEIROZ, C. O princípio da não-reversibilidade dos direitos fundamentais sociais: Princípios dogmáticos e prática jurisprudencial. Coimbra: Ed. Coimbra , 2006.

PEREIRA, P. A. P. Discussões conceituais sobre política social como política pública e direito de cidadania. In: BOSCHETTI, I et al. Política social no capitalismo: tendências contemporâneas. São Paulo: Cortez, 2006. p. 87-108. 
PIOVESAN, F. Direitos humanos e direito constitucional internacional. 12. ed. rev. e atual. São Paulo: Saraiva, 2011.

. Direitos sociais, econômicos e culturais e direitos civis e políticos. Revista Sur, São Paulo, ano 1, n. 1, p. 21-47, $1^{\circ}$ sem. 2004. Disponível em: <http://www2.ibam.org.br/municipiodh/biblioteca\%2FArtigos/flavia. pdf>. Acesso em: 9 mar. 2011.

SARLET, I. W. Algumas notas a respeito dos direitos fundamentais sociais e a proibição de retrocesso: desafios e perspectivas. Cadernos da AMATRA IV. Caderno de Estudos sobre Processo e Direitos do Trabalho, Porto Alegre: Amatra IV, ano v, n. 13, p. 13-47, 2010.

Dignidade da pessoa humana e direitos fundamentais na Constituição Federal de 1988. 7. ed. rev. atual. Porto Alegre: Livraria do Advogado, 2009.

. Eficácia dos direitos fundamentais. 10. ed. rev. atual. Porto Alegre: Livraria do Advogado, 2010.

A eficácia do direito fundamental à segurança jurídica: dignidade da pessoa humana, direitos fundamentais e proibição de retrocesso social no direito constitucional brasileiro. In: ROCHA, Carmen Lucia Antunes. Constituição e segurança jurídica: direito adquirido, ato jurídico perfeito e coisa julgada: estudos em homenagem a José Paulo Sepúlveda Pertence. Belo Horizonte: Fórum, 2004. p. 85-129.

SAVARIS, J. A. Uma teoria da decisão judicial da previdência social: contributo para superação da prática utilitarista. Florianópolis: Conceito, 2011.

SILVA, J. A. Curso de direito constitucional positivo. 21. ed. São Paulo: Malheiros, 2002.

SIMM, Z. Os direitos fundamentais e a seguridade social. São Paulo: LTr, 2005.

TAVARES, M. L. Direito previdenciário: regime geral de previdência social e regimes próprios de previdência social. 10. ed. Rio de Janeiro: Lumens Júris, 2008. 
WANG, D. W. L. Escassez de recursos, custos dos direitos e reserva do possível na jurisprudência do STF. Rev. Direito GV, Rio de Janeiro, v. 4, n. 2, p. 539-568, 2008. Disponível em: <http://www.direitogv.com. br/subportais/publica\%C3\%A7\%C3\%B5e/RD-08_10_Escassez\%20 de $\% 20$ recursos, $\% 20$ custos $\% 20$ dos $\% 20$ direitos $\% 20$ e $\% 20$ reserva $\% 20$ do\%20possivel_Daniel\%20Wang.pdf>. Acesso em: $1^{\circ}$ mar. 2010.

Recebido em: 15/03/12

Aprovado em: 14/02/13 